Faculdade

de Ciências Econômicas UFRGS
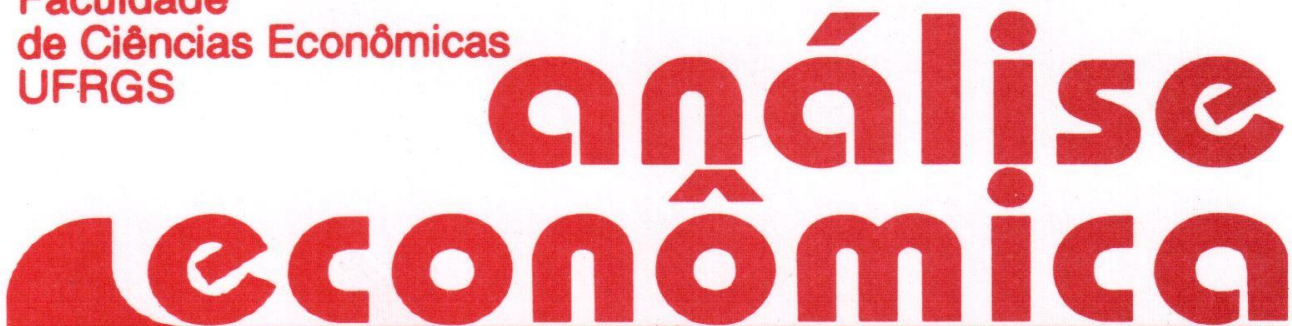

- globalização, Blocos REgIONAIS E O SETOR AGRÍ́COLA NO MERCOSUL Paulo D. Waquil

- globalização: ReALIdAde E UTOPIA

Gentil Corazza

- DO FOREIGN CURRENCY DEPOSITS DID THEY IMPROVE WELFARE?

Carlos A. Janada

- MACROECONOMIC INSTABILITY AND STRATEGIES OF TRANSNATIONAL CORPORATIONS IN BRAZIL

Reinaldo Gonçalves

- INFRASTRUCTURE, PUBLIC CAPITAL AND GROWTH IN THE BRAZILIAN ECONOMY

Stefano Florissi

+ EFEITOS DO PLANO REAL SOBRE O RIO GRANDE DO SUL Marcelo S. Portugal

- REgIONALIZAÇÃo dA MATRIZ dE INSUMO-PRODUTO E O IMPACTO DO AUMENTO DA PRODUÇÃO DE GRÃOS NO RS E NO BRASIL

Nali de Jesus de Souza

- IMPORTACõES DE LEITE E A PECUÁRIÁ LEITEIRA NO BRASIL Silvinha P. Vasconcelos

- ANPEC: CURSO PREPARATÓRIO

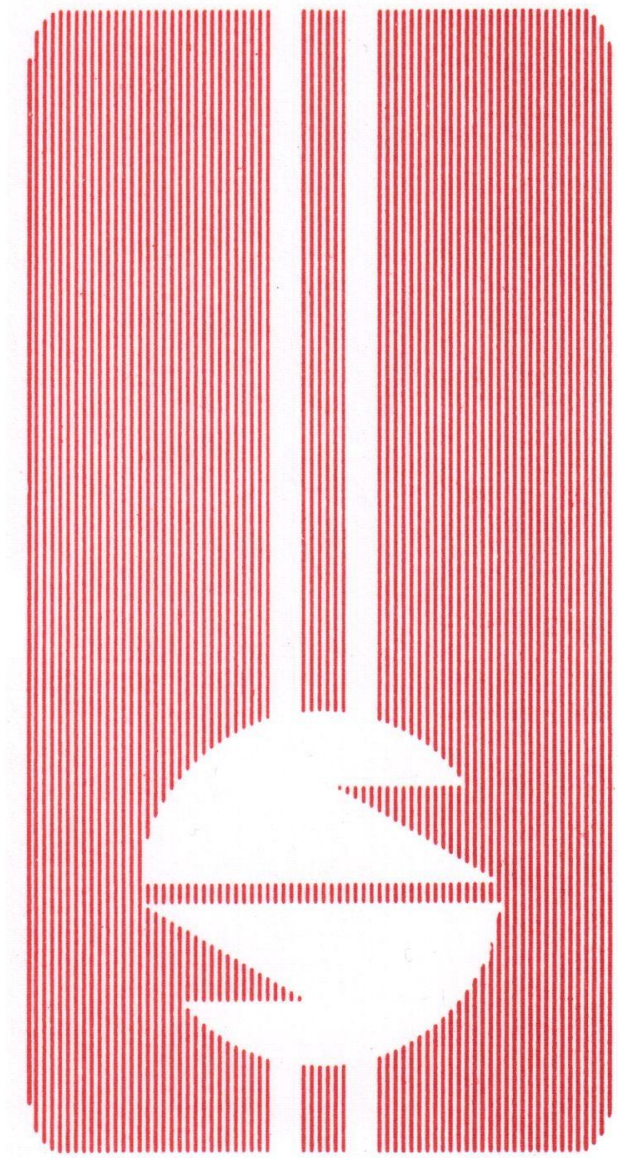


UNIVERSIDADE FEDERAL DO RIO GRANDE DO SUL

Reitor. Prof ${ }^{a}$. Wrana Maria Panizzi

FACULDADE DE CIÊNCIAS ECONÔMICAS

Diretor. Prof'. Otília Beatriz Kroeff Carrion

CENTRO DE ESTUDOS E PEQUISAS ECONÔMICAS

Diretor: Prof. Paulo Alexandre Spohr

DEPARTAMENTO DE CIÊNCIAS ECONÔMICAS

Chefe: Prof. Gentil Corazza

CURSO DE PÓS-GRADUAÇÃO EM ECONOMIA

Coordenador. Prof. Marcelo Savino Portugal

CURSO DE PÓS-GRADUAÇÃO EM ECONOMIA RURAL.

Coordenador. Prof. Carlos Guilherme A. Mielitz Netto

CONSELHO EDITORIAL: Achyles Barcelos da Costa, Aray Miguel Feldens, Carlos Augusto Crusius, Carlos Guilherme A. Mielitz Netto, Eugênio Lagemann, Fernando Ferrari Filho, Gentil Corazza, Marcelo Savino Portugal, Nali de Jesus de Souza, Otília Beatriz K. Carrion, Paulo Alexandre Spohr, Paulo Dabdab Waquil, Pedro Cezar Dutra Fonseca, Roberto Camps Moraes, Valter José Stülp, David Garlow (Wharton Econometrics Forecasts Association, E.U.A.), Edgar Augusto Lanzer (UFSC), Eleutério F. S. Prado (USP), Fernando de Holanda Barbosa (FGV/RJ), Gustavo Franco (PUC/RJ), João Rogério Sanson (UFSC), Joaquim Pinto de Andrade (UnB), Juan H. Moldau (USP), Werner Baer (Univ. de Illinois, E.U.A.).

COMISSÃO EDITORIAL: Fernando Ferrari Filho, Gentil Corazza, Paulo Dabdab Waquil, Marcelo Savino Portugal, Roberto Camps Moraes.

EDITOR: Nali de Jesus de Souza

SECRETARIA: Cláudia Porto Silveira, Jeferson Luis Bittencourt. Revisão de textos: Vanete Ricachescki.

FUNDADOR: Prof. Antônio Carlos Santos Rosa

Os materiais publicados na revista Análise Econômica são da exclusiva responsabilidade dos autores. É permitida a reprodução total ou parcial dos trabalhos, desde que seja citada a fonte. Aceita-se permuta com revistas congêneres. Aceitam-se, também, livros para divulgação, elaboração de resenhas e recensões. Toda correspondência, material para publicação (vide normas na terceira capa), assinaturas e permutas devem ser dirigidos ao seguinte destinatário:

PROF. NALI DE JESUS DE SOUZA

Revista Análise Econômica

Av. João Pessoa, 52

CEP 90040-000 PORTO ALEGRE - RS, BRASIL

Telefones: (051) 316-3348 e 316-3440

Fax: (051) 225-1067 


\section{GLOBALIZAÇÃO, FORMAÇÃO DE BLOCOS REGIONAIS E IMPLICAÇÕES PARA O SETOR AGRÍCOLA NO MERCOSUL*}

Paulo D. Waquil

\section{SINOPSE}

Este artigo discute as implicações para o setor agricola nos paises do Mercosul, dentro do contexto de globalização dos mercados e de formação de blocos regionais Inicialmente, apresenta o debate entre multilateralismo e regionalismo, apontando para a formação dos blocos regionais como uma alternativa viável à liberalização global dos mercados. A seguir, aborda os benefícios e custos do processo de integração regional. Então, salienta as implicações para o setor agricola no Mercosul, com indicações de ações a serem tomadas pelos setores público e privado.

\section{INTRODUÇÃO}

Recentemente o comércio internacional vem passando por transformações importantes, envolvendo principalmente a globalização dos mercados e a formação de blocos regionais. Em função da recomposição dos espaços, o comércio internacional tem crescido a taxas mais elevadas que as taxas de crescimento da produção mundial.

De acordo com dados do FMI, o PIB mundial cresceu a uma taxa anual de $3,4 \%$ no periodo de 1970 a 1994, enquanto o comércio internacional cresceu a uma taxa anual de $11,7 \%$ no mesmo periodo. Mesmo que nos anos mais recentes a taxa de crescimento anual do comércio internacional tenha sido reduzida com relação à década de 1970, esta taxa ainda é superior à taxa de crescimento do PIB no período. Por exemplo, no período de 1980 a 1994, a taxa de crescimento anual do PIB foi de $3,1 \%$, ao passo que a taxa de crescimento anual do comércio internacional foi de 5,8\%. A Figura 1, a seguir, ilustra esta situação, apresentando os indices para o PIB mundial e o comércio internacional, tendo como ano-base 1990 (indice $=100)$.

\footnotetext{
* Trabalho apresentado no Painel: "Mercosul, GATT e Comércio Internacional", no XXXIV Congresso Brasileiro de Economia e Sociologia Rural, em Aracaju, SE, de 05 a 08 de agosto de 1996.

Ph. D pela Universidade de Wisconsin, EUA. Professor Adjunto do Departamento de Ciências Econômicas e dos Cursos de Pós-Graduação em Economia (CPGE) e Economia Rural (CPGER) da Universidade Federal do Rio Grande do Sul (UFRGS). Av. João Pessoa, 31, Porto Alegre, RS, 90060-040, email: waquil@vortex.ufrgs.br.
}

Cód. AEA $\quad$ Palavras-chave:

712 globalização, integração regional, Mercosul.

\begin{tabular}{|l|l|l|r|}
\hline ANÁLISE ECONÔMICA & ANO 15 & Março/97 & p. 3-15 \\
\hline
\end{tabular}




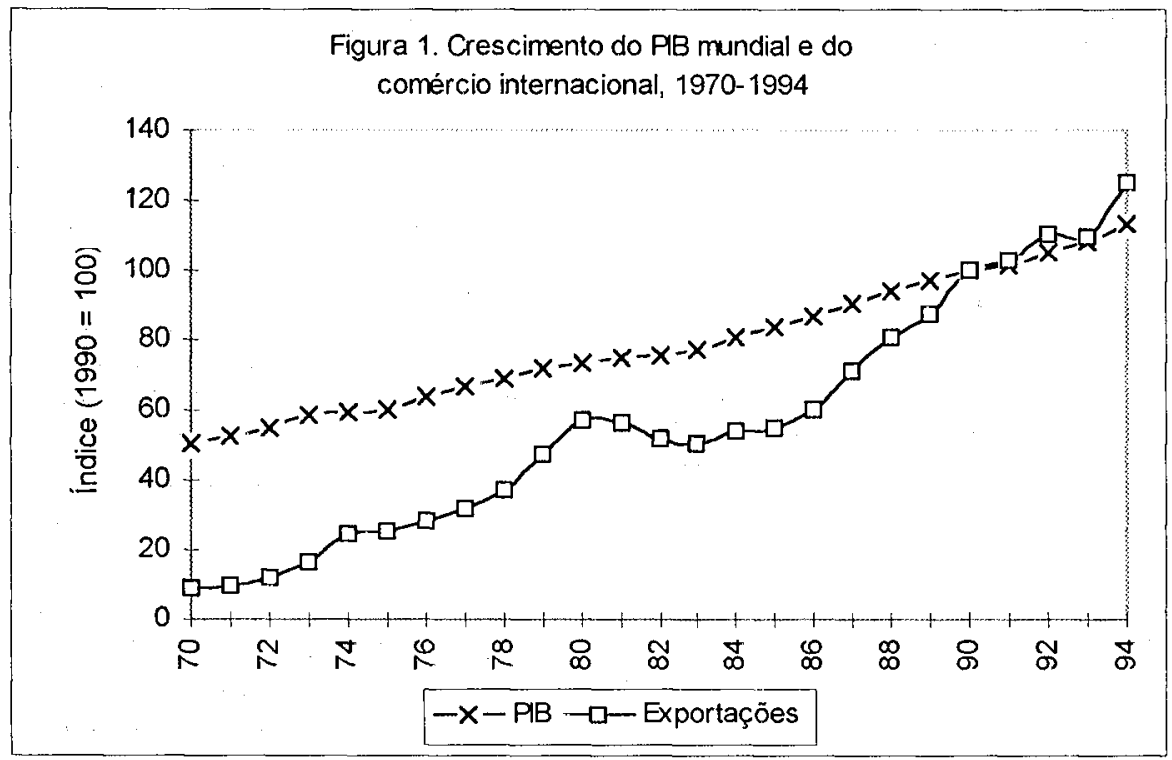

Fonte: IMF, 1996b.

Figura 2. Crescimento da produção e das exportações agricolas no mundo, 1970-1990

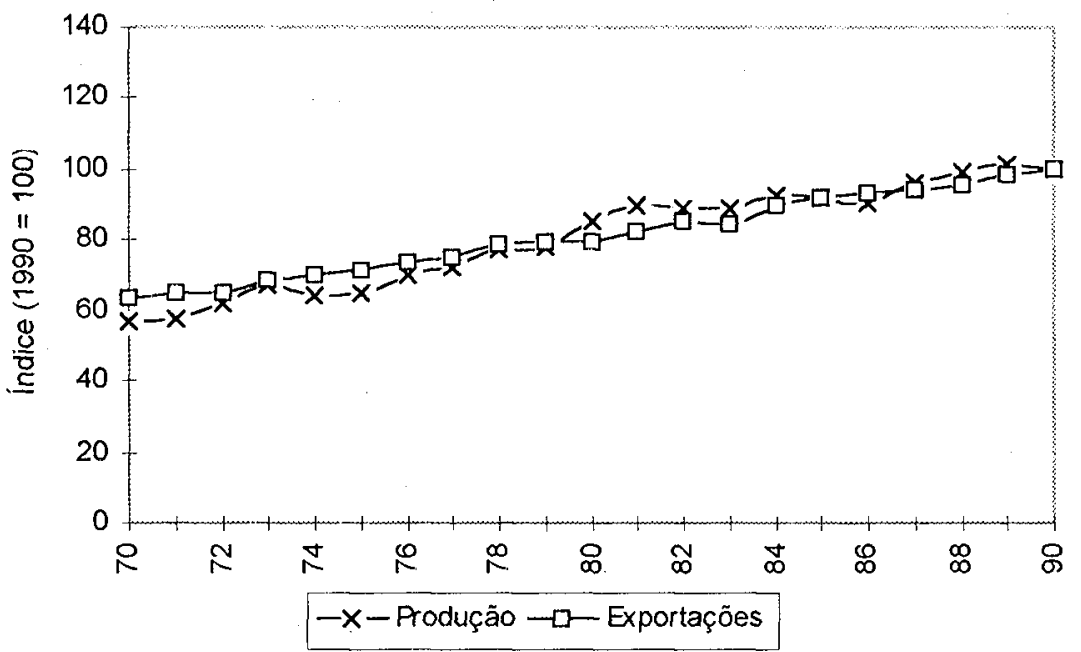

Fonte: FAO, 1990a; 1990b. 
No entanto, o comércio de produtos manufaturados apresentou crescimento substancialmente mais acentuado do que o comércio de produtos agrícolas. Conforme pode ser observado na Figura 2, o crescimento do comércio internacional de produtos agrícolas praticamente acompanhou o crescimento da produção agrícola no mundo nas duas últimas décadas. No período de 1970 a 1990 , a taxa de crescimento anual da produção agricola foi de $2,3 \%$, enquanto a taxa de crescimento anual do comércio internacional de produtos agrícolas foi de 2,9\%.

Em vista disto, é importante analisar o processo de globalização e formação de blocos regionais com implicações diferenciadas sobre a produção e fluxos de comercialização de produtos agrícolas. Este trabalho se propõe a discutir como o Mercosul se insere neste contexto de transformações do comércio internacional e, mais especificamente, quais as implicações para o setor agrícola no bloco.

O trabalho está organizado como segue: a próxima seção discute o tema multilateralismo e regionalismo, apontando para a formação de blocos regionais como uma alternativa viável à liberalização global dos mercados. A seção a seguir aborda os benefícios e custos do processo de integração regional, com um enfoque direcionado à formação do Mercosul. Então, as implicações para o setor agrícola no Mercosul são discutidas. Por fim, as conclusões do trabalho são apresentadas.

\section{MULTILATERALISMO E REGIONALISMO}

Integração: combinação de partes em um todo. Balassa (1973) define integração entre nações como um processo de remoção da discriminação entre diferentes nações. Fernandez (1992) argumenta que integração é um processo de relacionamento e dependência multidimensionais entre as nações participantes, que requer uma base comum de valores e preferências, e a percepção dos benefícios da integração, de forma que todos os participantes vão sustentar o processo. A localização geográfica, a infra-estrutura de transportes e comunicações, e o nivel de relações politicas, econômicas e culturais existentes entre as nações são aspectos importantes no processo de integração.

$\mathrm{Na}$ dimensão econômica, existem dois níveis de integração. o nível multilateral e o nivel regional. A integração multilateral envolve conferências internacionais para negociações com o alvo de reduzir tarifas e outras barreiras ao comércio internacional, sob o Acordo Geral sobre Tarifas e Comércio (GATT), hoje já sucedido pela Organização Mundial do Comércio (OMC). O acordo multilateral é baseado no princípio de não-discriminação; cada pais deve manter tarifas e outros regulamentos idênticos em relação a todos os outros países.

Por outro lado, integração regional é baseada no princípio de preferências, 
através da determinação de tarifas preferenciais para os paises participantes. Asșim, a integração regional envolve o acordo entre um conjunto de países, com o objetivo de liberalizar o comércio entre os participantes e possivelmente regulamentar barreiras com relação ao resto do mundo.

Sob o artigo XXIV do GATT, um bloco regional pode ser considerado consistente com a dimensão multilateral se o bloco satisfizer três requerimentos. Primeiro, o bloco deve incluir na liberalização do comércio uma quantidade substancial de todas as mercadorias comercializadas entre as nações participantes. Segundo, as nações que formam o bloco devem passar por um processo de notificação ao GATT. Terceiro, o bloco não pode ser formado para elevar novas barreiras ao comércio com nações fora do bloco (Belous e Hartley, 1990).

No entanto o recente ressurgimento de esquemas de integração regional tem conduzido a uma discussão sobre os beneficios potenciais do processo. O que é melhor para o mundo multilateralismo ou regionalismo? Devem-se manter as regras iguais para todos os paises ou reuni-los em blocos e estabelecer preferências entre os membros? Temas como a possibilidade de guerras tarifárias entre blocos regionais, o papel da OMC no futuro, ou as vantagens de expandir os atuais blocos regionais têm trazido uma série de controvérsias.

Inicialmente, a teoria de integração econômica aceitava que a integração regional necessariamente aumentava os niveis de bem-estar, e deveria ser encorajada, pois era vista como um movimento em direção ao livre comércio. No entanto, Viner (1950) demonstra que a integração regional não traz necessariamente uma melhoria, pois é um movimento em direção ao livre comércio apenas entre os paises membros, mas pode gerar proteção contra países fora do bloco. Ao examinar a combinação entre livre comércio e protecionismo, Viner introduz a distinção entre criação de comércio e desvio de comércio.

Bhagwati (1993) sugere que para preservar a abertura do comércio global através da integração regional é fundamental garantir que a adesão aos acordos regionais seja mantida aberta. No entanto, o autor indica que isto não é uma tarefa simples, e que a expansão da participação nos blocos regionais deverá continuar a ser manejada cuidadosamente. Ele indica, então, que o regionalismo pode ser tanto construtivo assim como destrutivo do sistema de comércio global, por causa da ocorrência de desvio de comércio.

Krugman (1993) também analisa o tema multilateralismo e regionalismo e levanta duas questões sobre o papel dos blocos regionais. Primeiro, a formação destes blocos conduz à criação de comércio ou ao desvio de comércio? A resposta parece ser clara: mais pesquisa é necessária. Segundo, existem razões fundamentadas para um direcionamento aos blocos regionais? $O$ autor sugere que, apesar da discussão ser solta e especulativa, a resposta é sim. Por vários motivos, 
a habilidade de sustentar uma solução cooperativa ao nível multilateral está declinando, enquanto ao nivel regional ela permanece forte.

Da mesma forma, Macadar (1996) salienta que a integração do sistema de comércio internacional obtida através das negociações do GATT é superficial e insuficiente para avançar de forma acelerada no processo de globalização dos mercados. Para isto, é necessária uma integração mais profunda, envolvendo práticas nacionais homogêneas e adequadas aos padrões internacionais, que eliminem as distorções e impedimentos estruturais ao comércio. Esta integração mais profunda dificilmente poderia ser alcançada nas negociações entre todos os países signatários do GATT. Por este motivo, os compromissos de integração mais profunda tendem a ser realizados seletivamente entre um conjunto mais reduzido de países

Outros estudos discutem os motivos políticos que conduzem à integração regional. Basicamente estes estudos assumem que os governos utilizam tarifas e outras barreiras para alcançar certos objetivos não-econômicos e que as políticas governamentais são uma resposta racional às demandas dos eleitores. Estes estudos identificam incentivos à integração regional quando o protecionismo é endógeno devido a compromissos políticos.

Assim, o processo de integração multilateral, reduzindo ou eliminando barreiras com base no princípio de não-discriminação conforme discutido no GATT, tem sido ineficaz para atingir a globalização dos mercados. Os diversos esquemas de integração regional, incentivados por motivos econômicos e políticos, aparecem como uma alternativa mais viável e representam uma tendência atual. $\dot{E}$ importante observar que cada bloco não pode ser visto isoladamente. Com diversos blocos sendo formados quase simultaneamente em todo o mundo, os efeitos de interação entre os blocos devem ser levados em conta, considerando-se então tanto o comportamento estratégico entre nações como o comportamento estratégico entre blocos.

\section{BENEFÍCIOS E CUSTOS DA INTEGRAÇÃO REGIONAL}

Conforme já foram descritas extensivamente na literatura sobre integração regional, as fontes de ganhos econômicos resultantes da formação de blocos regionais podem ser atribuidas a: ganhos de eficiência produtiva possibilitados pela especialização; economias de escala devido à concentração da produção; melhoria da posição de barganha nos mercados internacionais, possibilitada pelo aumento do tamanho do mercado integrado; ganhos de eficiência econômica resultantes da mobilidade de fatores; coordenação de politicas macrueconômicas e setoriais; e unificação de objetivos, tais como pleno emprego, altas taxas de crescimento econômico e distribuição de renda.

Gandolfo (1994) indica que os benefícios da integração regional são maiores: quanto maior for o grau de competitividade entre as nações participantes, por 
causa da expansão das indústrias mais eficientes; quanto maiores forem as barreiras antes do acordo entre as nações que formam o bloco regional; quanto menores as barreiras com relação ao resto do mundo, devido à menor possibilidade de desvio de comércio; quanto maior for o bloco, à medida que aumenta a possibilidade de criação de comércio. Em suma, a formação de blocos regionais traz maiores ganhos para nações cujas economias são inicialmente competitivas, mas potencialmente complementares.

Outro tema importante a considerar são as características pertinentes a países em desenvolvimento. A integração regional entre paises em desenvolvimento tem algumas distinções fundamentadas nas diferenças estruturais destes paises com relação aos países desenvolvidos. Duas características são a menor participação da produção industrial e o baixo nivel de comércio entre os países em desenvolvimento. É possivel que a integração regional seja a estratégia ótima para alguns países em desenvolvimento, em vez da integração multilateral, em vista de que algumas teorias de desenvolvimento assumem a necessidade de proteção para encorajar a industrialização. E, por causa do baixo nivel de comércio entre os paises em desenvolvimento, a importância da criação e desvio de comércio é menor.

Çom relação ao Mercosul, Ala Rue e Lavergne (1992) enfatizam que historicamente o nivel de comércio dentro da região tem sido pequeno e limitado a certos produtos, mas com a formação do bloco existe a possibilidade de aumentar consideravelmente o fluxo de comércio entre os paises participantes, e sustentar este aumento ao longo do tempo. Quando o acordo foi assinado, em 1991, o comércio anual entre Argentina, Brasil, Paraguai e Uruguai somava apenas US\$ 4,5 bilhões; dois anos depois, já era em torno de US\$ 8,0 bilhões; e em 1995, já ultrapassava US $\$ 12,5$ bilhões. No entanto os valores acima ainda são pequenos quando comparados com o comércio anual total com outros países fora do bloco.

A Tabela 1 apresenta as exportações dos paises do Mercosul, conforme o destino, em 1990 e 1995. De acordo com os dados abaixo, as exportações intraregionais (fluxo entre os países do Mercosul) aumentaram em $206,7 \%$ no periodo de 1990 a 1995 , enquanto as exportações totais destes paises aumentaram em $52,5 \%$.

Pode-se observar, entretanto, que o comércio anual entre os países do Mercosul correspondia a apenas $8,9 \%$ das exportações totais em 1990, passando a $17,9 \%$ em 1995, um número ainda relativamente pequeno. $O$ Brasil exportava aos parceiros do Mercosul apenas $4,2 \%$ do total de exportaçóes em 1990, passou a exportar $13,2 \%$ do total em 1995. Assim, a integração regional entre os países que formam o Mercosul enfoca mais os ganhos de escala criados pela ampliação dos mercados, especialização apropriada e aumento do poder de barganha nos mercados internacionais. 
Tabela 1. Exportações dos paises do Mercosul, conforme o destino - 1990 e 1995 (em bilhões de US\$)

\begin{tabular}{|c|c|c|c|c|c|c|c|}
\hline $\begin{array}{l}1990 \\
\mathrm{De}:\end{array}$ & Argentina & Brasil & Paraguai & uguai & $\begin{array}{l}\text { Mercosul } \\
\text { (A) }\end{array}$ & $\begin{array}{l}\text { Total } \\
\text { (B) }\end{array}$ & $\begin{array}{l}A / B \\
(\%) \\
\end{array}$ \\
\hline Argentina & - & 1.423 & 147 & 263 & 1.833 & 12.353 & 14,8 \\
\hline Brasil & 645 & - & 380 & 295 & 1.320 & 31.414 & 4,2 \\
\hline Paraguai & 55 & 312 & - & 12 & 379 & 959 & 39,5 \\
\hline Uruguai & 82 & 506 & 6 & - & 594 & 1.693 & 35,1 \\
\hline Mercosul & & & & & 4.126 & 46.419 & 8,9 \\
\hline $\begin{array}{l}1995 \\
\mathrm{De}:\end{array}$ & Argentina & Brasil & Paraguai & uguai & $\begin{array}{c}\text { Mercosul } \\
(A)\end{array}$ & $\begin{array}{l}\text { Total } \\
\text { (B) }\end{array}$ & $\begin{array}{l}A / B \\
(\%) \\
\end{array}$ \\
\hline Argentina & - & 3.685 & 657 & 607 & 4.949 & 20.967 & 23,6 \\
\hline Brasil & 4.041 & - & 1.301 & 812 & 6.154 & 46.506 & 13,2 \\
\hline Paraguai & 79 & 467 & $\cdots$ & 12 & 558 & 1.180 & 47,3 \\
\hline Uruguai & 268 & 702 & 25 & - & 995 & 2.117 & 47,0 \\
\hline Mercosul & & & & & 12.656 & 70.770 & 17,9 \\
\hline
\end{tabular}

Fonte: IMF, 1996a.

Entretanto o processo de integração (seja multilateral ou regional) e inserção nos mercados internacionais envolve também custos aos participantes, causados por limitações dos graus de liberdade na implementação de políticas nacionais. A integração leva ao enfraquecimento das politicas públicas nacionais, afetando principalmente as politicas protecionistas. Desta forma, a integração entre nações significa um deslocamento do papel do Estado.

A integração no nivel regional pode envolver também custos causados por desvios de comércio. Tais custos ocorrem quando importações mais baratas provenientes de terceiros paises são substituidas por importações mais caras de países do bloco devido ao acesso preferencial e prática de regras de origem ou tarifas externas comuns. Kume (1996) verifica que a análise dos coeficientes de exportação/PIB e importação/PIB segundo o destino e a origem, respectivamente nos biênios $89 / 90$ e 93/94, assinala a presença de desvio de comércio no Mercosul, com efeitos negativos sobre o bem-estar.

Já que existe potencial para desvio de comércio num acordo de integração regional, e os benefícios e custos (ou vantagens e desvantagens) não são facilmente determinados, Rajapatirana (1994) sugere que a busca de estratégias que minimizem as perdas com a formação do bloco. Tais estratégias podem envolver: (a) baixos niveis de proteção com relação a terceiros países, reduzindo os custos causados pelo desvio de comércio; (b) formação de blocos abertos, isto é, mantendo aberta a possibilidade de adesão de novos membros; (c) aumento da competição dentro do bloco, pela remoção de normas que possam limitar esta competição; (d) busca de maior liberalização com o resto do mundo; e (e) 
coordenação de políticas macroeconômicas, mobilizando forças para uma melhor alocação dos recursos dentro do bloco.

No entanto o próprio fenômeno da globalização não é isento de assimetrias e contradições (Macadar, 1996). As assimetrias manifestam-se pelo fato de que aproximadamente $85 \%$ do comércio mundial se concentra atualmente nos países desenvolvidos. As contradições manifestam-se no novo surto de pressões protecionistas adotadas pelos países desenvolvidos, através da aplicação de barreiras não-tarifárias, que afetam principalmente os países em desenvolvimento.

A autora sugere que a formação de blocos regionais pode favorecer o aumento das assimetrias existentes, pois os países excluidos ficam mais expostos a conflitos comerciais, ao desvio de comércio e ao redirecionamento dos investimentos diretos estrangeiros em favor dos países membros dos blocos.

Macadar (1996) cita como exemplo as propostas que o Mercosul vem recebendo para formar acordos de livre comércio com o NAFTA e a União Européia. Tais propostas comportam o risco de aprofundar ainda mais as assimetrias já existentes em nível multilateral, à medida em que os benefícios resultantes de tais acordos forem menores que os custos para os paises em desenvolvimento. Os benefícios destes acordos de livre comércio seriam dados pelo acesso facilitado a outros mercados, através da redução de barreiras tarifárias e não-tarifárias. Por outro lado, os custos seriam dados pela necessidade de ajustes estruturais, envolvendo temas como regras de origem, direitos de propriedade intelectual relacionados com o comércio, relações trabalhistas e meio ambiente.

Com isto, é importante ter cautela na formalização de acordos de livre comércio com outros blocos regionais. De imediato, os países do Mercosul devem se concentrar na consolidação do bloco e no aprofundamento das relações com outros países sul-americanos, em busca da integração entre um número maior de países e da formação de uma área de livre comércio na América do Sul. Posteriormente, mais fortalecido, o bloco deve promover o acesso facilitado aos outros blocos, seguindo as concessões já negociadas no GATT.

Mais um aspecto importante são os efeitos (benefícios e custos) diferenciados sobre os diversos setores e grupos de agentes envolvidos. Mesmo que a formação de um bloco regional traga benefícios liquidos para os paises envolvidos, pode haver perdas para determinados setores ou grupos de agentes. Pode-se fazer necessário, então, um esquema de compensações baseadas nas variações de bem-estar causadas pelo processo de integração. Estas compensações em geral se referem à realocação de recursos de uma parte do bloco para outra, ou de um setor para outro. Entre as várias formas de compensação, estão o auxílio a indústrias prejudicadas pela competição com outros países membros, 
desenvolvimentó de infra-estrutura, e ajuda direta a áreas menos desenvolvidas na região.

\section{IMPLICAÇÕES PARA O SETOR AGRÍCOLA NO MERCOSUL}

O Mercosul objetiva o estabelecimento de um único mercado entre Argentina, Brasil, Paraguai e Uruguai, fundamentado na livre circulação de bens e serviços, no estabelecimento de tarifas externas comuns, e na coordenação de políticas macroeconômicas e setoriais. No entanto a maior dificuldade reside na coordenação das politicas públicas das nações que formam o bloco.

Diversos estudos apontam o setor agricola como um dos mais sensiveis no processo de integração, indicando que os impactos (benefícios e custos) da formação do Mercosul são diferenciados em função da região geográfica e da estrutura produtiva em questão. Estes impactos não dependem apenas das políticas macroeconômicas e setoriais, mas também da viabilização da infraestrutura de transportes, armazenagem e processamento da produção. A sensibilidade das cadeias produtivas ao processo de integração regional não se dá pelos diferenciais de custo de produção nas propriedades agricolas, mas sim pelo custo final dos produtos agroindustriais nos centros de consumo.

Deve-se considerar, então, não a competitividade da produção agrícola, mas sim do sistema como um todo, envolvendo também o processamento, a distribuição e o consumo dos bens. Nas etapas de produção e processamento são importantes os aspectos ambientais e tecnológicos. Com a integração dos mercados, mais importância é dada às etapas seguintes, de distribuição e consumo dos bens. Outros aspectos passam a ter maior relevância, como a disponibilidade de informações, o poder de barganha e o acesso às preferências dos consumidores.

A fim de obter o máximo de benefícios aos menores custos possiveis, dois tipos de ações devem ser abordadas: as ações do setor público e as ações do setor privado.

Primeiro, do lado do setor público, a integração dos mercados e coordenação de políticas públicas exigem condições de igualdade de competição entre as nações, não apenas com relação aos bens exportáveis, mas também com relação aos bens destinados ao consumo doméstico. Faz-se necessária a eliminação das distorções ao comércio, através da redução da carga tributária sobre insumos e produtos agrícolas, da imposição de direitos compensatórios sobre bens importados com subsídios de outros países, da redução das taxas de juros e da redução da sobrevalorização da taxa de câmbio. Compete também ao setor público (possivelmente num esforço conjunto com o setor privado) o investimento 
em educação e capacitação profissional, a geração e difusão de tecnologias e de informações, visando explorar as vantagens competitivas, as oportunidades do mercado e obter um crescimento sustentável.

Por exemplo, Jank (1993) salienta que vários estudos indicam que a incidência de impostos sobre a produção agricola e agroindustrial no Brasil é superior à incidência de impostos nos demais parceiros do Mercosul, determinando distorções importantes na competitividade entre os países. Cabe, então, ao setor público a eliminação de tais distorções, favorecendo a competição dentro do bloco.

Segundo, do lado do setor privado existe a necessidade de ajustes, de uma mudança de postura, de uma maior preocupação com a escolha de alternativas, com a administração da produção, com a comercialização e orientação para 0 mercado. Para as cadeias mais sensiveis (aquelas que têm perdas maiores do que os benefícios trazidos pela integração), pode ser necessária a reconversão produtiva, buscando reorientar a produção no caso de perda de competitividade. Este processo de reconversão deve envolver a recomposição dos bens produzidos, o avanço tecnológico, a relocalização das indústrias e o uso de contratos estratégicos (por exemplo, alianças e terceirização de atividades).

Entretanto existe ainda uma carência de estudos que analisem os impactos sobre cadeias especificas e que apontem adequadamente onde e como os setores público e privado devem agir.

Alguns estudos têm sido desenvolvidos com o objetivo de comparar custos de produção de diversos produtos agricolas entre os países que formam o Mercosul, e assim analisar a competitividade entre estes paises (IEPE, 1992; MGAyP, 1992; entre outros). Estes estudos analisam somente o lado da oferta dos bens em questão, embora sejam importantes para indicar algumas distorções na formação dos custos de produção. Contudo é importante ressaltar a diferença entre competitividade entre países e competitividade entre firmas. Mesmo que diversos estudos indiquem que um dado pais tem custos de produção de um certo bem mais elevados que seus parceiros, isto não significa que todas as firmas neste dado país tenham custos de produção mais elevados. Aquelas firmas que se mostrarem competitivas devem permanecer no processo produtivo, enquanto as outras devem passar por ajustes e buscar alternativas através da reconversão produtiva.

A reconversão produtiva também é indicada por Wilkinson (1996) como a solução para os setores não competitivos ou ineficientes, embora políticas específicas para este fim não estejam muito evidentes e financiamentos menos ainda. $O$ autor discute as possibilidades para a produção familiar no cenário de integração regional, indicando que a produção familiar pode ser competitiva se certos obstáculos institucionais forem removidos. Ele cita três argumentos como 
fundamentais: o acesso ao crédito, a remoção do viés tecnológico e a necessidade de incorporar uma perspectiva de custos sociais totais

Por outro lado, outros estudos têm implementado modelos de equilíbrio espacial de produtos, a fim de encontrar a alocação ótima de recursos em diferentes setores nos paises que formam o bloco (Gutierrez Perez, 1988; Stein Neto, 1991; Villwock, 1993; Olsen, 1994; Waquil, 1995). Estes estudos levam em consideração tanto o lado da oferta dos bens em questão, quanto o lado da demanda, através de modelos de equilibrio parcial. Além disto, possibilitam a simulação de cenários alternativos e a análise de políticas, verificando os impactos de diferentes conjuntos de medidas sobre os diversos grupos de agentes envolvidos e assim servindo como fundamento para o processo de tomada de decisões.

Não apenas a competitividade dentro do bloco deve ser considerada. Além das relações entre os paises que formam o Mercosul, é importante ainda considerar as relações do bloco com o resto do mundo. A agricultura é um setor crucial para todos os paises do bloco, e demonstra especialização considerável. O Mercosul é exportador liquido de carne bovina, aves, grãos, frutas, café e outros produtos agroindustriais. Desta forma, não apenas os benefícios e custos resultantes da redução das barreiras ao comércio entre os paises que formam o bloco regional devem ser considerados. Mas também devem ser levadas em conta as possiveis implicações com relação ao resto do mundo como, por exemplo, o aumento do tamanho do mercado e a melhoria da posição de barganha.

\section{CONCLUSÕES}

Este trabalho discute a inserção do Mercosul no contexto de globalização dos mercados, abordando as implicações para o setor agrícola no bloco regional. No debate entre multilateralismo e regionalismo, indica-se que a integração multilateral tem sido ineficaz para atingir a globalização e que a formação de blocos regionais aparece como uma alternativa mais viável e uma tendência atual. Neste sentido torna-se importante para os paises que formam o Mercosul a busca da consolidação do bloco e o aprofundamento dos vínculos com outros vizinhos sulamericanos.

No processo de integração, as fronteiras passam a ter nova função. As fronteiras não são mais concebidas como limites, mas sim como mecanismos de coordenação de ações. As fronteiras, anteriormente discriminantes, agora passam a atuar com uma função facilitadora do transporte e do comércio, em busca de maximizar os benefícios líquidos auferidos com a formação do bloco. "Os impactos" sobre o setor agrícola são diferenciados para cada região e cada 
cadeia produtiva. Com a integração dos mercados é cada vez mais importante a disponibilidade de informações, afetando todas as etapas do sistema produtivo. São indicadas diversas ações visando à obtenção do máximo de benefícios aos menores custos possiveis.

Para o setor público, sugere-se principalmente a eliminação das distorções ao comércio e o investimento na geração e difusão de tecnologias e informações. Por outro lado, para o setor privado as ações sugeridas envolvem ajustes, orientação para o mercado e reconversão da produção quando necessária. É importante ressaltar a necessidade de mais estudos que indiquem e quantifiquem os benefícios e os custos do processo para os agentes envolvidos, identifiquem alternativas, assim como as possiveis compensações que se façam necessárias, a fim de dar fundamentos ao processo de tomada de decisões.

\section{BIBLIOGRAFIA}

ALA RUE, P. e N. Lavergne. Antecedentes y perspectivas del Mercosur. Buenos Aires: Fundación Friedrich Ebert - CISEA, 1992.

BALASSA, B. The theory of economic integration. London: George Allen \& Unwin, 1973.

BELOUS, R. e R. Hartley. The growth of regional trading blocs in the global economy. Washington, D.C.: National Planning Association, 1990.

BHAGWATI, A. Regionalism and multilateralism: an overview. In: MELO, J. e PANAGARIYA, A. (eds.). New dimensions in regional integration. Cambridge: Cambridge University Press, 1993.

CENTRO DE ESTUDOS E PESQUISAS ECONÔMICAS (IEPE). A agropecuária sulbrasileira no contexto do Mercosul. Porto Alegre, IEPE/UFRGS, 1992.

FAO. Production yearbook. Rome: FAO, 1990a.

Trade yearbook. Rome: FAO, 1990b.

FERNANDEZ, W Mercosur economía, politica y estrategia en la integración. Montevideo: Fundación de Cultura Universitaria, 1992.

GANDOLFO, G. International economics I: the pure theory of international trade. $2^{a}$ ed. Berlin: New York: Springer-Verlog, 1994.

GUTIERREZ PEREZ, J. A integração Brasil - Argentina: um estudo da competitividade na produção de grãos. Porto Alegre, IEPE/UFRGS, 1988 (tese de mestrado em Economia Rural).

IMF Direction of trade statistics yearbook. Washington, D.C.: IMF, 1996a. International financial statistics yearbook. Washington, D.C.: IMF, 1996b.

JANK, M. Mercosul: efeito das políticas publicas sobre a competitividade. Revista de Economia e Sociologia Rural, v. 31, n 4, p. 349-69, 1993.

KRUGMAN, P. Regionalism versus multilateralism: analytical notes. In: MELO, J. e PANAGARIYA, A (eds.). New dimensions in regional integration. Cambridge: Cambridge University Press, 1993.

KUME, H. Mercosul - 1995: uma avaliação preliminar. Economia Brasileira em Perspectiva. Rio de Janeiro: IPEA, p 157-185, 1996.

MACADAR, B. Política comercial brasileira: os dilemas da inserção internacional. Ensaios FEE, v.17, n.1, p. 234-52, 1996.

MINISTERIO DE GANADERIA, Agricultura y Pesca (MGAyP). Estudios sobre competitividad de productos agropecuarios en el Mercosur. Montevideo, MGAyP/GTZ, 1992.

OLSEN, T. The implications of the Mercosur economic integration on trade, economic welfare and government policy in wheat, maize and soybean sectors. Cornell University, 1994 (M.Sc. thesis)

RAJAPATIRANA, S. The evolution of trade treaties and trade creation: lessons for Latin America. Paper presented at the Annual Regional Conference of the International Cooperative Alliance, held in Quito, Ecuador, on August 23-27, 1994. 
STEIN NETO, B. A vitivinicultura do Rio Grande do Sul e a integração econômica Brasil - Argentina. Porto Alegre, IEPE/UFRGS, 1991 (tese de mestrado em Econ Rural).

VILLWOCK, L Os impactos econômicos do Mercosul sobre as cadeias de produção do trigo, soja, milho, suinos e aves. Porto Alegre: IEPE/UFRGS, 1993 (tese de mestrado em Econ. Rural).

VINER, J. The customs union issue. New York: Carnegie Endowment for International Peace, 1950.

WAQUIL., P. Primal-dual spatial equilibrium model with intermediate products: application to the agricultural sector in the Mercosur. University of Wisconsin - Madison, 1995 (Ph D dissertation).

WILKINSON, J. Integração regional e o setor agroalimentar nos paises do Mercosul: a produção familiar na encruzilhada. Porto Alegre: Ensaios FEE, v. 17, n. 1, p.155-84, 1996.

\section{ABSTRACT \\ GLOBALIZATION, FORMATION OF REGIONAL BLOCS AND IMPLICATIONS TO THE AGRICULTURAL SECTOR IN THE Mercosul}

The paper discusses the implications to the agricultural sector in the Mercosul countries, within the context of market globalization and formation of regional blocs. First, it presents the debate between multilateralism and regionalism, pointing out to the formation of regional blocs as a feasible alternative to the global market liberalization. Next, it discusses the benefits and costs of the process of regional integration. Then, it points out the implications to the agricultural sector in the Mercosul, with indications of actions to be taken by the public and private sectors. 